\title{
EFEITOS DA LUZ, TEMPERATURA E ESTRESSE DE ÁGUA NA GERMINAÇÃO DE SEMENTES DE CAESALPINIA PELTOPHOROIDES \\ BENTH. (CAESALPINOIDEAE) ${ }^{(1)}$
}

\author{
FERNANDA GOLLO A. FERRAZ-GRANDE ${ }^{(2)}$; MASSANORI TAKAKI ${ }^{(3)}$
}

\begin{abstract}
RESUMO
As sementes de Caesalpinia peltophoroides absorvem água rapidamente e após 9 horas acumulam o conteúdo de $56 \%$ de água e perdem mais lentamente, necessitando de cerca de 20 horas para perder completamente a água absorvida. As sementes de Caesalpinia peltophoroides germinam na faixa de temperaturas de 15 a $25{ }^{\circ} \mathrm{C}$, e não possuem fotossensibilidade independentemente dos tratamentos luminosos e das temperaturas testadas. Verificou-se que com a diminuição do potencial de água, ocorre nas sementes uma redução na germinabilidade e na velocidade de germinação sob luz branca. Sob condições de estresse de água, observa-se fotossensibilidade, em sementes de Caesalpinia peltophoroides, sendo a germinação inibida pela luz branca mediada pelo pigmento fitocromo.
\end{abstract}

Palavras-chave: fotossensibilidade, germinabilidade, sibipiruna, fitocromo.

\section{ABSTRACT \\ EFFECTS OF LIGHT, TEMPERATURE AND WATER STRESS ON SEED GERMINATION IN CAESALPINIA PELTOPHOROIDES BENTH. CAESALPINOIDEAE}

Seeds of Caesalpinia peltophoroides absorb water and reach rapidly 56\% of their water content after 9 hours. They lose water slowly, requiring 20 hours to completely lose imbibed water. Seeds of Caesalpinia peltophoroides germinated in the temperature range 15 to $25{ }^{\circ} \mathrm{C}$. They did not show light sensitivity under different light types. We observed that low water potential reduced the germinability and germination rate. Under water stress those seeds were inhibited by white light mediated by phytochrome.

Key words: light sensitivity, geminability, sibipiruna, phytochrome.

$\left({ }^{1}\right)$ Trabalho realizado com recursos da FAPESP, FUNDUNESP e CNPq. Recebido para publicação em 10 de agosto de 2004 e aceito em 7 de fevereiro de 2006.

$\left(^{2}\right)$ Doutora pelo Programa de Pós-Graduação em Ciências Biológicas, Biologia Vegetal, Departamento de Botânica, UNESP, Caixa Postal 199, 13506-900 Rio Claro (SP).

$\left({ }^{3}\right)$ Departamento de Botânica, UNESP, 13506-900 Rio Claro (SP). Email: massa@rc.unesp.br 


\section{INTRODUÇÃO}

O processo de embebição de água pelas sementes é dependente da temperatura e da água disponível e a capacidade de retenção da água absorvida determinará o sucesso do processo de germinação (Bansal et al., 1980; Perez e Moraes, 1991).

A ação da luz na germinação de sementes é mediada pelo fitocromo, cuja ação em sementes fotossensíveis foi discutida por CASAL e SÁNCHEZ (1998). O fitocromo é uma família de cinco formas distintas (A, B, C, D e E) codificadas por cinco genes distintos em Arabidopsis thaliana e em Lycopersicon esculentum (Whitelam e Devlin, 1997). O fitocromo B é utilizado pelas plantas para detectar a razão entre a luz vermelha e vermelho-extremo (CASAL e SÁNCHEZ ,1998). Sementes insensíveis à luz sob condições de estresse de água passam a ter sensibilidade à luz e segundo TAKAKI (2001) esse processo é mediado pelo fitocromo A. Por outro lado, a sensibilidade à luz em sementes de Jacaranda mimosifolia em condições de estresse de água, foi devido ao fitocromo B (Socolowski e TAKAKI, 2004).

Dentro da faixa de temperatura em que as sementes de uma determinada espécie germinam, há geralmente uma temperatura ótima. A faixa de temperatura na qual as sementes germinam refletem muitas vezes as características térmicas do habitat onde tais espécies ocorrem (MedinA, 1977). A interação entre a luz e a temperatura foi bem representada por Sмітн (1975) com diferentes lotes de sementes de Lactuca sativa. Em lotes diferentes de sementes de alface ocorreram sensibilidades diferentes à luz, mas em todos os lotes estudados, em baixas temperaturas, não houve sensibilidade à luz, e as sementes germinaram tanto na luz como no escuro. Por outro lado, em temperaturas altas observou-se termodormência e em temperaturas intermediárias, fotossensibilidade, e as sementes germinaram somente sob luz branca. Assim, da mesma forma que a disponibilidade de água, a sensibilidade das sementes pode variar em função da temperatura.

Caesalpinia peltophoroides Benth, popularmente conhecida como sibipiruna é uma planta semidecídua, heliófita, indiferente às condições físicas do solo, de médio a rápido crescimento, é também indicada para plantios mistos em áreas degradadas de preservação permanente (LorenzI, 1992). Tendo em vista a importância da espécie Caesalpinia peltophoroides para a utilização em repovoamento de áreas degradadas (SANTANA e SANTOS, 1999), arborização e paisagismo, devido à atenuação da radiação solar, que proporciona temperatura ambiente mais amena
(Bueno-Bartholomei e LabaKi, 2003), estudou-se o comportamento fisiológico das suas sementes, analisando a influência da luz através do fitocromo e sua interação com a temperatura e o estresse de água na sensibilidade à luz no processo de germinação.

\section{MATERIAL E MÉTODOS}

As sementes de Caesalpinia peltophoroides Benth. utilizadas foram coletadas no chão logo após dispersão feita por pelo menos 15 árvores localizadas no Campus da UNESP de Rio Claro. Diariamente, o local era varrido e as sementes recém-caídas foram coletadas. Esse procedimento foi feito durante um período de cinco dias (julho de 2001). Após a coleta, as sementes foram armazenadas em frascos de vidro fechados com tampa plástica selada com parafilm ${ }^{\circledR}$ (BRAND, Alemanha) e mantidas a $5{ }^{\circ} \mathrm{C}$ em uma incubadora para BOD (FANEM, modelo 347). Na ocasião do armazenamento, o teor de água das sementes foi de $12 \%$, determinado pela manutenção das sementes em estufa a $105{ }^{\circ} \mathrm{C}$ até peso constante. O início dos experimentos foi logo após a coleta das sementes sendo todos os experimentos realizados em um período máximo de três meses. As sementes não foram tratadas antes de serem realizados os experimentos. Foram utilizados quatro lotes de vinte sementes em placas de Petri de $90 \mathrm{~mm}$ de diâmetro para cada tratamento, com duas camadas de papel filtro umedecido com $10 \mathrm{~mL}$ de água destilada ou com a solução de polietilenoglicol. Para evitar a alteração da concentração da solução de polietilenoglicol do meio de incubação, as sementes foram retiradas e colocadas em placas de Petri com a nova solução a cada dois dias. O mesmo processo foi realizado com as sementes incubadas com água destilada.

Para o estudo da embebição, foram colocadas quatro amostras de 20 sementes para embebição em água destilada, sob luz branca e a 25 ${ }^{\circ} \mathrm{C}$ em uma sala climatizada, e o aumento do peso foi acompanhado gravimetricamente com o uso de uma balança analítica (Mettler modelo H31AR). A mesma quantidade de amostras de sementes foi usada para se obter a porcentagem de perda de água. As sementes foram pré-embebidas por um período de 36 horas e deixadas em placas de Petri sem as tampas, sob luz branca a $25{ }^{\circ} \mathrm{C}$. A porcentagem de embebição e de perda de água foi determinada conforme ARASAKI e Felippe (1987). O teor de água das sementes foi determinado conforme descrito por PiÑA-Rodrigues (1988). 
A determinação da temperatura miníma, ótima e máxima, foi feita pela incubação das sementes em câmaras de germinação para BOD (FANEM, modelo 347) na faixa de 10 a $35{ }^{\circ} \mathrm{C}$, com intervalos de $5{ }^{\circ} \mathrm{C}$. As sementes com protrusão da radícula, com pelo menos $2 \mathrm{~mm}$ de comprimento, foram consideradas germinadas e descartadas com as leituras diárias. Os experimentos duraram no máximo 30 dias.

A influência da luz branca na germinação foi analisada pelo uso de lâmpadas fluorescentes tipo

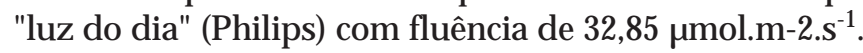
Nas condições de escuro contínuo, as sementes mantidas no interior de placas de Petri, conforme já descrito, foram acondicionadas em gerbox pretos. Para se obter a luz vermelha $(V)$ e vermelho-extremo (VE) foram usados respectivamente, filtros acrílicos vermelho sob luz fluorescente, e filtros acrílicos vermelho e azul sob luz incandescente (AMARAL-BAROLI e TAKAKI, 2001). As sementes germinadas no escuro, sob luz vermelha e luz vermelho extremo, foram contadas sob luz verde de segurança. Os espectros das fontes luminosas foram os mesmos descritos por Amaral-Baroli e TAKAKI (2001) e obtidos com o uso de um espectrorradiômetro LI-1800 (LI-COR, E.U.A.). Para os experimentos de estresse de água, as sementes foram incubadas sob diferentes potenciais de água $(-0,2 ;-0,3$ e $-0,4 \mathrm{MPa})$, obtidos com o uso de diferentes concentrações de polietilenoglicol 8000 (PEG), segundo Michel (1983), na temperatura ótima, determinada de acordo com o experimento do efeito das diferentes temperaturas, na luz e no escuro. Como controle as sementes foram incubadas em água destilada.

Os cálculos de germinabilidade e velocidade da germinação foram obtidos através das equações citadas em Labouriau e AgUdo (1987). As comparações dos valores médios de porcentagem e velocidade de germinação foram feitas através da análise de variância. Os valores das porcentagens de germinação foram transformados em arco seno $\sqrt{\%}$, segundo SNEDECOR e Cochram (1967) e as médias comparadas pelo teste de Tukey.

\section{RESULTADOS E DISCUSSÃO}

Observou-se nas sementes de Caesalpinia peltophoroides uma porcentagem de umidade de $12,68 \%$ na época de realização dos experimentos. Verificou-se que a embebição foi relativamente rápida até 9 horas, atingindo $56 \%$ de conteúdo de água e a partir daí tornou-se mais lenta, até sua estabilização, obtida após 33 horas (Figura 1). Aproximadamente após três dias ocorreu a protrusão da radícula na temperatura de $25{ }^{\circ} \mathrm{C}$. Os resultados revelaram que nas sementes de Caesalpinia peltophoroides não ocorreu dormência tegumentar embebendo água rapidamente.

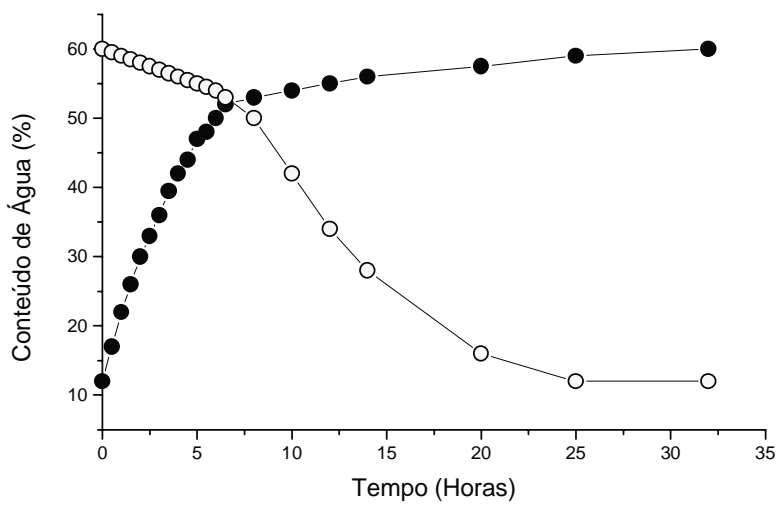

Figura 1. Curvas de embebição (-•-) e dessecacão (-o-) das sementes de Caesalpinia peltophoroides Benth, a $25{ }^{\circ} \mathrm{C}$.

Pela curva de dessecação, observa-se que as sementes perdem seu conteúdo de água em 20 horas, quando ocorre a volta ao seu conteúdo inicial (Figura 1). Portanto, a perda de água das sementes de Caesalpinia peltophoroides é mais lenta que sua embebição. Esses dados sugerem que as sementes de Caesalpinia peltophoroides, uma vez embebidas, perdem lentamente água através do tegumento e o processo de germinação poderá não ocorrer, caso o substrato utilizado não forneça água no período de um dia. Assim, os resultados revelam que, em viveiros, o substrato deverá ser mantido úmido com irrigações diárias para a obtenção da germinação de sementes de Caesalpinia peltophoroides.

Com relação às temperaturas cardeais, para as sementes de Caesalpinia peltophoroides, a temperatura mínima foi de $15{ }^{\circ} \mathrm{C}$, a máxima de $30{ }^{\circ} \mathrm{C}$ e sendo a ótima de $25^{\circ} \mathrm{C}$, pois nessa temperatura ocorreu maior porcentagem de germinação dentro de um menor espaço de tempo (Figura 2). Sementes incubadas acima da temperatura máxima, extravasaram substâncias para o meio, com o desenvolvimento de microrganismos como fungos e bactérias, indicando sua deterioração.

Nas sementes de Caesalpinia peltophoroides não houve fotossensibilidade, pois não ocorreu variação significativa nas porcentagens finais da germinabilidade para luz branca e escuro bem como para os valores médios da germinação observados para os diferentes tratamentos luminosos. Além disso, não foi observada variação significativa dos resultados de germinação entre a qualidade de luz dentro de uma mesma temperatura (Figura 2). 

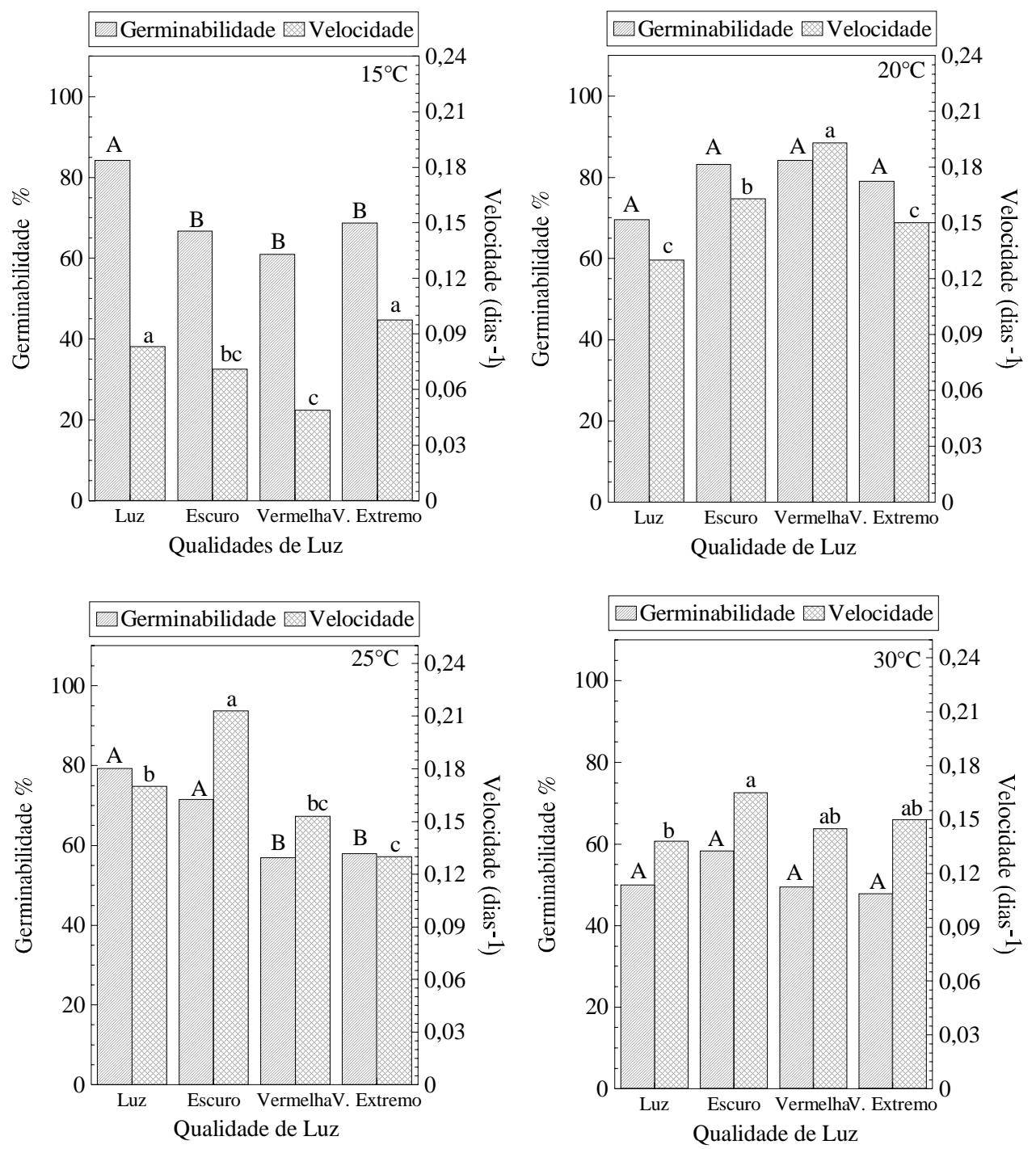

Figura 2. Efeitos de diferentes qualidades de luz na germinação e velocidade das sementes de Caesalpinia peltophoroides em diferentes temperaturas. Médias seguidas pelas mesmas letras não diferem entre si ao nível de probabilidade adotado de $0,05 \%$.

A dependência da velocidade de germinação à temperatura de incubação foi observada a $15^{\circ} \mathrm{C}$ que foi a menor de todas as temperaturas testadas, embora com as porcentagens finais de germinação semelhantes às de 20 e $25^{\circ} \mathrm{C}$ (Figura 2). Verificamos ainda que, houve diferenças significativas nos valores da velocidade em cada temperatura, para as sementes incubadas na luz branca, escuro, luz vermelha (V) e vermelho-extremo (VE). A $15{ }^{\circ} \mathrm{C}$ as maiores velocidades foram observadas nos tratamentos sob VE e luz branca; já a $20{ }^{\circ} \mathrm{C}$ foi verificada para o tratamento com $\mathrm{V}$ e a $25{ }^{\circ} \mathrm{C}$ e $30{ }^{\circ} \mathrm{C}$ sob escuro contínuo. Pelos resultados, nota-se que os efeitos das diferentes qualidades de luz dependem da temperatura de incubação, como descrito por SMITH (1975), indicando a participação do fitocromo no controle da germinação de sementes. A ação das diferentes qualidades de luz, especialmente V e VE revelam a participação do fitocromo $B$ no processo, conforme relatado por CASAL e SÁNCHEZ (1998).

Algumas espécies de sementes que, normalmente, não são sensíveis à luz, passam a ser quando submetidas a condições de estresse de água, como por exemplo em Jacaranda mimosifolia (SOKOLOWSKI e TAKAKI, 2004).

Observam-se em sementes de Caesalpinia peltophoroides maiores porcentagens de germinação e valores de velocidade no escuro contínuo, em condições de estresse de água, com um decréscimo na porcentagem de germinação, conforme foi diminuindo o potencial de água imposto às sementes. Por outro 
lado, houve redução na velocidade de germinação sob estresse de água, mas sem diferenças significativas de $-0,2$ a -0,4 MPa (Figura 3). Segundo TAKAKI (2001), a ação inibitória da luz branca, em condições de estresse de água, na germinação de sementes é devido ao fitocromo A.
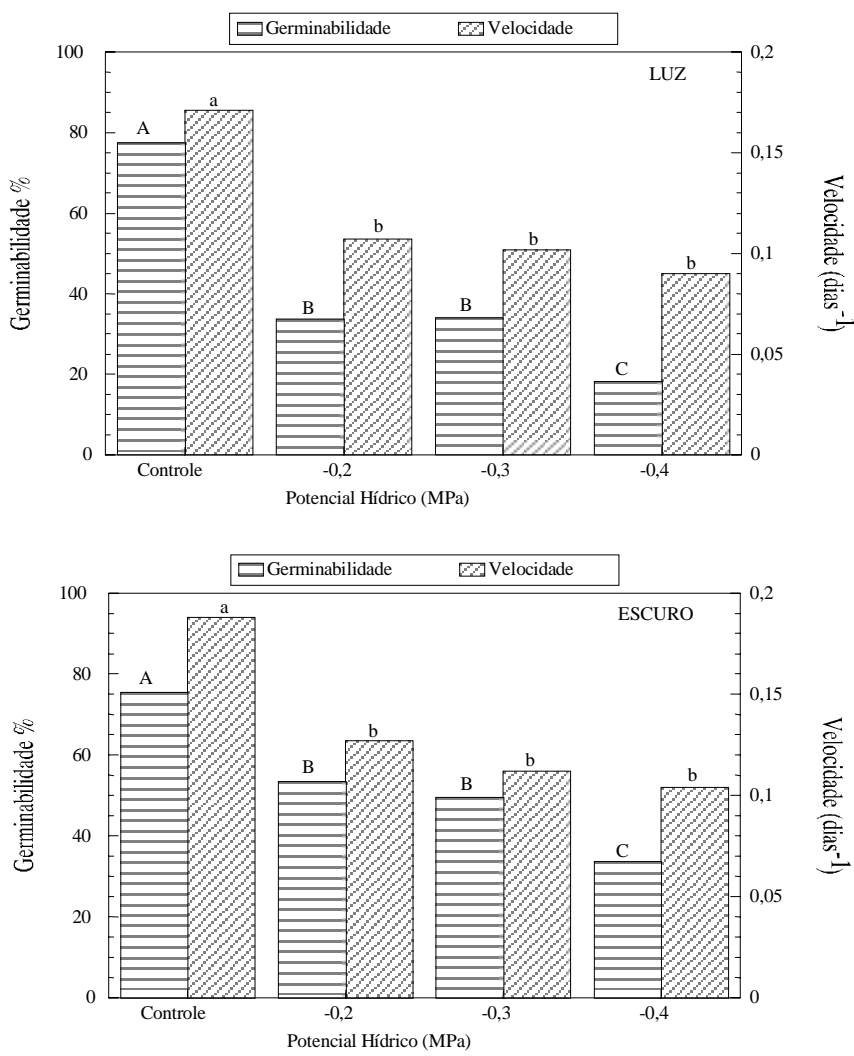

Figura 3. Efeitos de diferentes potenciais hídricos na germinação e velocidade das sementes de Caesalpinia peltophoroides na luz branca e escuro contínuo na temperatura de $25{ }^{\circ} \mathrm{C}$. Médias seguidas pelas mesmas letras não diferem entre si ao nível de probabilidade adotado de $0,05 \%$.

Poucos são os estudos realizados sobre o efeito do estresse de água na sensibilidade à luz em sementes de espécies arbóreas. A maioria dos trabalhos foi realizada com espécies cultivadas ou herbáceas. Em sementes de Cucumis satious e Helianthus annuus observa-se um fotoblastismo negativo sob baixo potencial de água. Estresse hídrico pode também levar a uma reversão da fotossensibilidade, como na germinação de sementes de Chenopodium album que, normalmente, são fotoblásticas positivas passam, sob estresse de água, a fotoblásticas negativas (BEWLEY e BLACK, 1994).
A disponibilidade de água é um fator determinante do sucesso do processo da germinação de sementes quando o fator temperatura e tensão de oxigênio não são limitantes (LABOURIAU, 1982). Assim, em condições de estresse de água, a hidratação de várias proteínas pode ocorrer com velocidades diferentes podendo assim, levar à diminuição na velocidade de germinação; quando o grau de estresse de água for maior, pode levar, inclusive, à inibição completa do processo de germinação (MAYER e PolJAKOfF-MAYBer, 1989).

TAKAKI (1990) verificou que em condições de estresse de água a germinação de sementes de Oryza sativa foi inibida sob irradiação com luz branca. Da mesma forma, com o decréscimo do potencial de água do meio, o crescimento das raízes, das folhas e do coleóptilo, foi inibido, sob luz branca. Segundo o autor, o sistema de fitocromo é usado pelas plantas para monitorar o potencial de água do solo, induzindo a germinação das sementes quando for favorável ao crescimento da plântula. Com base nos resultados do presente trabalho, sugere-se que em sementes de Caesalpinia peltophoroides, há a participação do fitocromo B em condições de disponibilidade de água e em condições de estresse de água, pelo fitocromo A.

\section{REFERÊNCIAS}

AMARAL-BAROLI, A.; TAKAKI, M. Phytochrome controls seed germination in Bidens pilosa L. (Asteraceae) by very low fluence response. Brazilian Archives of Biology and Technology, Curitiba, v.44, p.121-124, 2001.

ARASAKI, F.R.; FELIPPE, G.M. Germinação de Dalbergia violacea, uma espécie dos cerrados. Revista Brasileira de Biologia, São Carlos, v. 47, p. 457-463, 1987.

BANSAL,R.P., BHATI, P.R., SEN,D.N. Differential specificity in water imbibition of Indian arid zone. Biologia Plantarum, Praga, v.22, p.327-31, 1980.

BEWLEY, J.D., BLACK,M. Seeds: physiology of development and germination. New York: Plenum Press, 1994. 445p.

BUENO-BARTHOLOMEI, C.L., LABAKI, L.C. How much the change os species of trees affect their solar radiation attenuation. Proceeding of the International Conference on Urban Climate, Lodz, v.1, p.1-4, 2003.

CASAL, J.J, SÁNCHEZ, R. Phytochromes and seed ghermination. Seed Science Research, New Delhi, v. 8, p. 317329, 1998.

LABOURIAU, L.G.; AGUDO, M. On the physiology of seed germination in Salvia hispanica L. I. Temperature effects. Anais da Academia Brasileira de Ciências, Rio de Janeiro, v. 59, p. 37-56, 1987. 
LORENZI, H. Árvores brasileiras: manual de identificação e cultivo de plantas arbóreas nativas do Brasil. Nova Odessa: Plantarum, 1992, 360p.

MAYER,A.M.; POLJAKOFF-MAYBER,A. The germination of seeds. Oxford, Perganon Press, 1989. 270p.

MEDINA, E. Introducción a la Ecofisiologia Vegetal. Washington: Secretaria Geral da O.E.A., 1977. 97p.

MICHEL, B.E. Evaluation of water potentials of solutions of polyethyleneglycol 8000 both in the absence and presence of other solutes. Plant Physiology, Stanford, v. 72, p. 66-70, 1983.

PEREZ,S.C.J.A., MORAES,J.A.P.V. Influência do estresse hídrico e do $\mathrm{pH}$ no processo germinativo da algarobeira. Pesquisa Agropecuária Brasileira, Brasília, v.26, p.981-8, 1991.

PIÑA-RODRIGUES,F.C.M. Manual de análise de sementes florestais. Campinas: Fundação Cargill, 1988.

SANTANA, J.R.F.S., SANTOS, G.M.M. Arborização do Campus da UEFS: exemplo a ser seguido ou um grande equívoco. Sitientibus, Feira de Santana, v. 20, p. 103-107, 1999.
SMITH, H. Phytochrome and Photomorphogenesis: an introduction to the photocontrol of plant development. London: Mc Graw Hill, 1975. 235p.

SNEDECOR, G.W.; COCHRAN, W.G. Statistical methods. Iowa: The Iowa State University Press, 1967. 240p.

SOCOLOWSKI, F.; TAKAKI, M. Germination of Jacaranda mimosifolia (D.Don - Bignoniaceae) seeds: effects of light, temperature and water stress. Brazilian Archives of Biology and Technology, Curitiba, v.47, p. 785-792, 2004.

TAKAKI, M. Effect of water stress on seed germination and seedling growth in Oryza sativa L. Biologia Plantarum, Praga, v.32, p.238-40, 1990

TAKAKI, M. New proposal of classification of seeds by forms of phytochrome instead of photoblastism. Brazilian Journal of Plant Physiology, Lavras, v. 13, p.103-107, 2001.

WHITELAM, G.C.; DEVLIN, P.F. Roles of different phytochromes in Arabidopsis photomorphogenesis. Plant Cell and Environment, Logan, v. 20, p. 752-758, 1997. 